\title{
Implementing Standardized Statistical Measures and Metrics for Public Services in Archival Repositories and Special Collections Libraries
}

\author{
Amanda K. Hawk \\ Louisiana State University, USA
}

\begin{abstract}
Developed by a three-year task force composed of members of the Association of College and Research Libraries' Rare Books and Manuscripts Section and the Society of American Archivists, the "Standardized Statistical Measures and Metrics for Public Services in Archival Repositories and Special Collections Libraries" report provides these types of institutions-for the first time-with commonly accepted guidelines for quantifying use and measuring impact. In response to the report, Louisiana State University Libraries began efforts to apply the newly approved measures and metrics in the special collections unit. We first evaluated the existing statistical data collected in past years, moving away from paper and pencil tallies toward robust software solutions, primarily through two applications: SpringShare's LibApps platform and Aeon, a request and workflow management software for special collections. We identified new areas of reporting to implement in 2018. We initiated the changes and launched the final version of the reporting measurements on July 1, 2018, to coincide with the new fiscal year. This paper presents one potential approach to implementing the Standardized Statistical Measures and Metrics task force report.
\end{abstract}

\section{Introduction}

The recent creation and approval of public services measures and metrics specifically tailored to special collections and archival institutions fills a long-term need for the field. While organizations like the Association of Research Libraries (ARL) have collected and published statistical data from research libraries for decades, ${ }^{1}$ there is no single dataset available for special collections. In recent fiscal years, ARL has encouraged the submission of special collections data related to expenditures, staffing, and the number of library presentations and participants, with an open suggestion to submit additional data at each institution's discretion. ${ }^{2}$ The statistics currently reported to ARL, however, do not tend to fit the unique needs of special collections and archives or fully represent our multifaceted areas of impact. In addition, without agreedupon and precisely defined methods of measurement, special collections and archives have thus far faced difficulties in attempting to analyze data across institutions nationwide.

In 2012, Joyce Chapman and Elizabeth Yakel examined efforts in the field (both past and present) to gather, analyze, and apply operational data and strongly advocated for the need to "achieve consensus on definitions for qualitative metrics to facilitate comparisons between institutions." ${ }^{3}$ Chapman and Yakel echoed many librarians' and archivists' desires to implement data-driven decision-making and evidence-based practices in the workplace, but noted the lack of publications or publicly available information documenting these efforts. ${ }^{4}$ As the conversation around standardized measures grew, members of the special collections and archives community presented at conferences; wrote articles for journals, newsletters, and blogs; and shared ideas on this topic in person and via social media. This was all with the intention of determining (1) how to accurately measure special collections data and, by extension, meaningfully assess our work, and (2) how to demonstrate the impact of special collections and archives. ${ }^{5}$

In 2014, the Society of American Archivists (SAA) and ACRL's Rare Books and Manuscripts Section (RBMS) formed a joint task force to establish standardized statistical measures for public services. After a community survey and several opportunities for public feedback, the ACRL and SAA governing bodies approved the standards in October 2017 and January 2018 respectively. According to the task force members, the standards provide archivists and librarians with a set of "precisely defined, practical measures based upon commonly accepted professional practices that can be used to establish statistical data collection practices to support the assessment of public services and their operational impacts at the local institutional level." 6 
Many institutions have moved into an implementation phase following the approval of the report. Further conversations about creating a national repository to store special collections data continue at various levels within SAA and RBMS. ${ }^{7}$ At LSU, the creation of industry-wide standards for public services statistics has prompted attention to greater accuracy in record keeping and inspired valuable discussions about how to use the data we collect to improve our services. This paper also considers LSU's continued challenges in data collection and highlights some of the many ways the data is being applied to decision-making.

\section{Implementation in Practice: Improving Data Collection}

In February 2018, I joined the Louisiana State University Libraries as head of public and research services in special collections. In this role, my charge was to coordinate assessment efforts for special collections. My arrival presented an opportunity to review the statistical efforts already in place, as well as to begin tracking additional measures and metrics recommended in the task force report. In surveying the current state of data collection, I found some public services measures tracked via paper forms in the reading room, then input on spreadsheets. Other valuable measures were not tracked at all-though primarily due to a lack of staffing in public services.

LSU Special Collections was already tracking seven of the eight basic measures ${ }^{8}$ detailed in the Standardized Statistical Measures and Metrics report: user association, reference questions received, visits, items checked out, events, instruction sessions, and exhibits. We were not actively tracking data related to the final basic measure-web page views-though it would be possible to gather this data, if needed. The unit was also collecting about 15 of the 40 advanced measures detailed in the report, with spotty data collection available for other recommended metrics. I created a new spreadsheet template to track monthly statistics by fiscal year and organized and color-coded the data fields according to the eight basic categories of measurement in the report.

While gaps in data collection did exist, LSU Special Collections was actively using two platforms capable of generating robust public services statistics: Aeon and Springshare's LibApps. Aeon, developed by Atlas Systems and currently used by at least 70 research institutions in the US, is a highly customizable workflow management software for special collections and archives. ${ }^{9}$ Features include online patron registration and requesting, item routing and tracking, and an activities module for staff management of instruction sessions, exhibits, and other special events using collection materials. LSU launched Aeon in July 2015. LibAnswers, primarily used by LSU to track reference transactions, is one of the tools in the SpringShare suite. ${ }^{10} \mathrm{LSU}$ also utilizes the LibGuides and LibInsight modules. More than 5,700 libraries across the world use SpringShare products. LSU Libraries began using the SpringShare products in January 2015.

With the ability to customize Aeon and LibAnswers to fit our needs, I set about ensuring our systems could generate the recommended measures and metrics. Aeon functions as a large database, storing a wealth of patron information and collection usage data that can be queried either through custom SQL searches or through a series of standard reports related to reading room use (e.g., characteristics of all users or new users, frequency of collection use, checkouts per day/month/year). Aeon users also receive access to AtlasBI, which offers real-time business intelligence reports that are easy to filter as well as a variety of options for creating data visualizations. (See Figure 1.) 
Figure 1. LSU Special Collections data from the AtlasBI reading room analytics dashboard, July 2018.

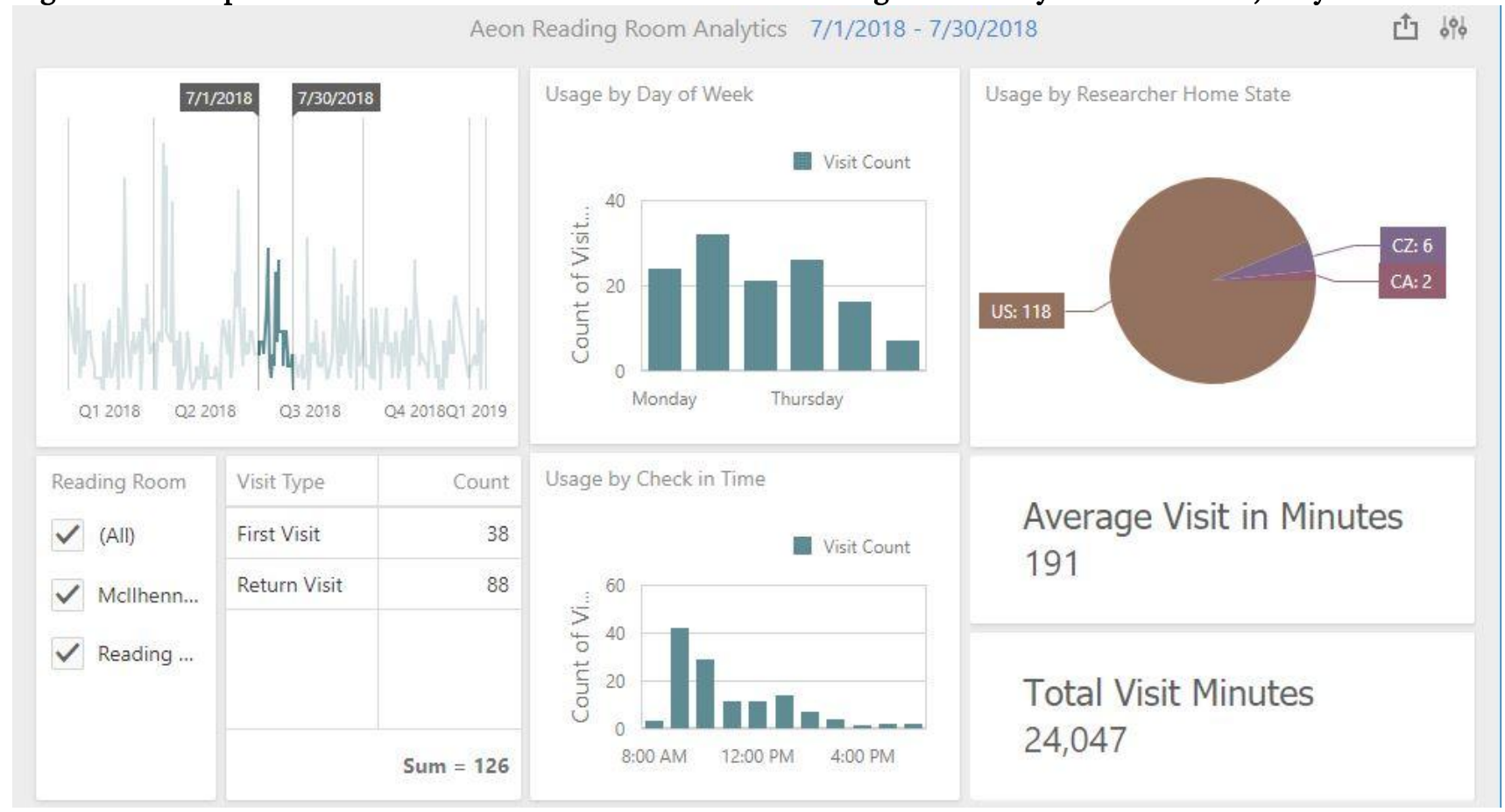

LSU Special Collections staff had also created two custom Aeon reports prior to my arrival, both of which aid in generating useful metrics: one report tracks the number of interlibrary loan requests in a given time frame and the second counts the total number of collection units requested in the reading room. ${ }^{11}$ The second report produces more accurate circulation figures, as it takes into account a single Aeon transaction that may represent multiple volumes, reels, or serials. I primarily used the AtlasBI interface and the standard reports to generate the necessary statistical measures from Aeon. The multitude of reporting options within the Aeon software meant I did not need to spend time customizing new reports, but focused instead on running the monthly reports for all of the newly added data points from the task force report.

Despite having access to SpringShare's LibAnswers product, LSU Special Collections was not utilizing the platform fully. The reference transaction form used from January 2015 to early 2018 captured a limited number of data points, making any long-term, meaningful analysis difficult. The form included the question type (a holdover from the main library's reference form), the outcome (e.g., answered, forwarded to other staff member or library), the interaction type (i.e., communication method), and the desk location where a reference transaction occurred. (See Figure 2.) 
Figure 2. LSU Special Collections' LibAnswers reference transaction form, used from 2015 to 2018.

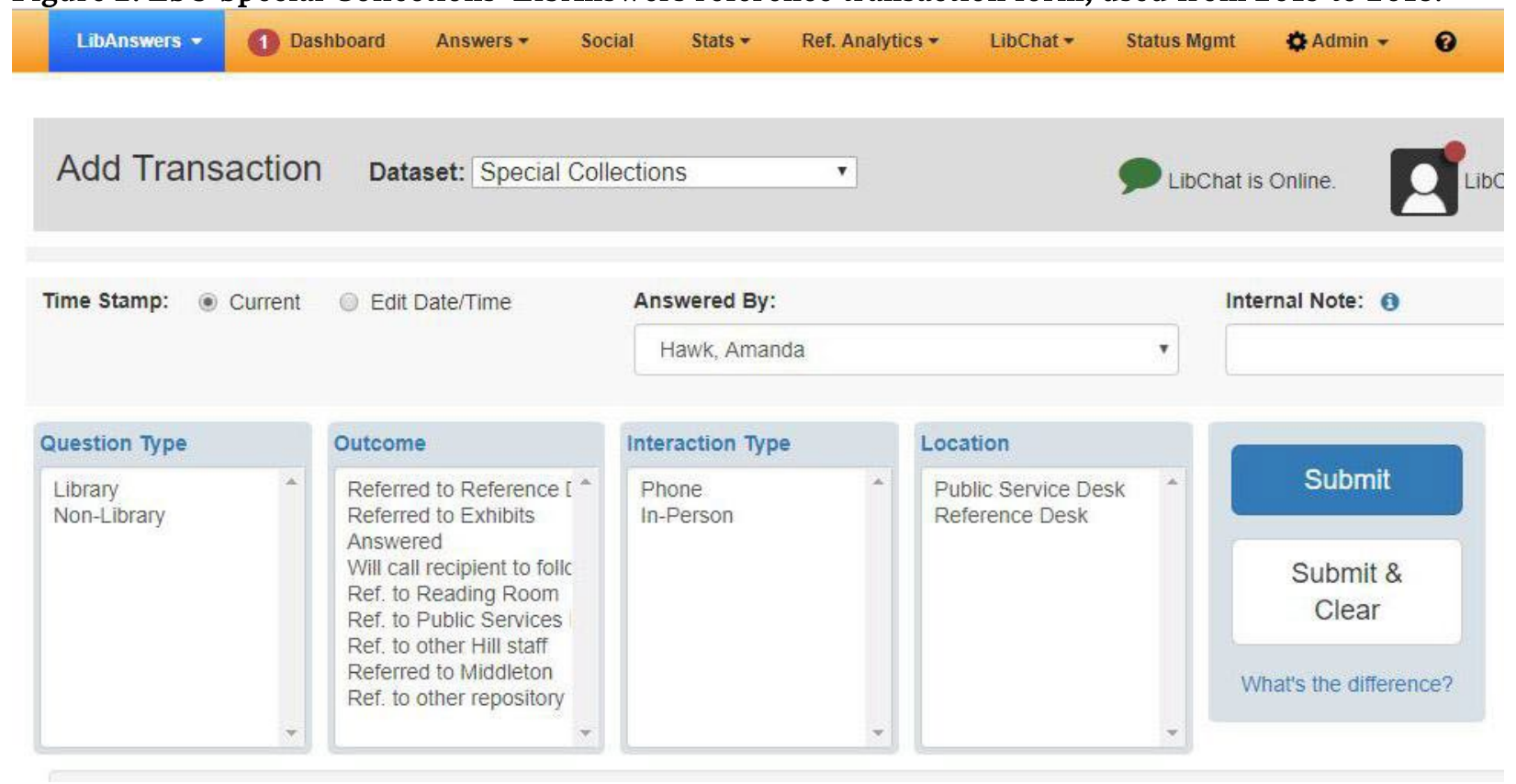

I identified two primary functions needing improvement when evaluating this tool: (1) the ability to record and track specific questions and their corresponding replies, and (2) the inclusion of remote reference into the manual transaction form.

To address the first item, we added question and answer boxes to the reference transaction form. The Q\&A boxes were not enabled because the special collections form was based on the form first used by LSU's main library. The addition of open text boxes in these fields allow patrons and staff to include detailed questions and answers. Staff can paste entire email exchanges into the answer field as keyword-searchable text. I also added to the form new fields corresponding with two advanced measures recommended in the Reference Transactions section of the task force report (time spent responding to a question and question purpose), plus patron affiliation and collection type used. (See Figure 3.)

I easily corrected the second action item by adding field options for email and international email under Interaction Type and sharing the new policy with staff. Prior to my arrival at LSU, all remote reference email exchanges received via email were printed and filed alphabetically by the last name of the correspondent. This method is a reliable and low-tech option for tracking reference requests, but it limits the staff's ability to query the data or identify statistical trends. The inclusion of remote reference transactions into the same dataset as the in-person and phone queries already tracked in LibAnswers created a comprehensive body of data. Library staff can now add information to the LibAnswers reference dataset in two ways-by replying to tickets submitted online by patrons, or by manually filling out a transaction form recording references received in person, by phone, and through personal email messages. 
Figure 3. LSU Special Collections' updated LibAnswers reference transaction form, implemented July 1, 2018.

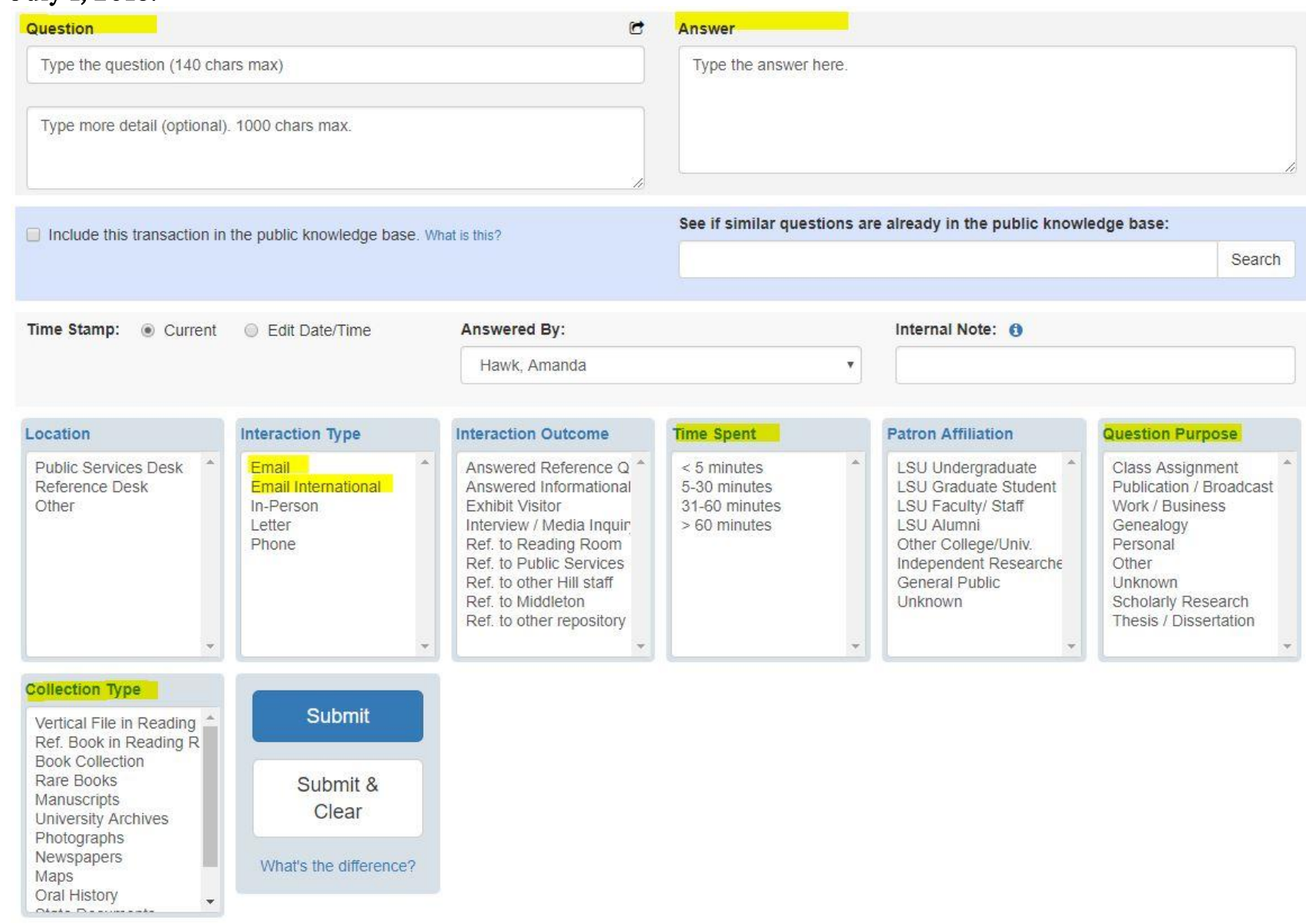

\section{Continued Challenges in Data Collection}

LSU Special Collections staff faced several problem areas during the implementation, some of which continue to impact our data gathering. One drawback to using the LibAnswers reference transaction form for data collection is the inability to make changes to data points. Rearranging, renaming, or deleting values from the menu options on the transaction form will generate incorrect data points for all previously entered transactions. For example, if the options for Interaction Type were originally listed in the following order: In-Person, Letter, Phone, but changed to: Email, Email International, In-Person, Letter, Phone, then past transactions assigned as "In-Person" now display as "Email" in the database. To eliminate confusion, we can download and save the current dataset and start fresh with perfected fields and values at the start of the next fiscal year. Staff looking for legacy data would need to consult the saved spreadsheet.

We also encounter difficulties in accurately counting certain statistical measures despite our improved methods of collection. Quantifying the impact of remote users of special collections is particularly complicated and requires combining reports from both platforms. LibAnswers provides the number of reference transactions received from phone calls, letters, or email, and Aeon tracks interlibrary loan requests and duplication orders. These numbers give us the total number of remote transactions, but not the total number of unique remote patrons served. Researchers' names are not always recorded in LibAnswers, and cross-referencing names between the two systems would require staff time and labor beyond what is realistic to expend.

Achieving accuracy in quantifying the total number of reference transactions presents its own challenges. The task force report includes the following stipulations about data collection of reference transactions: 
"Count questions from users working in the Reading Room if the response requires staff to employ their knowledge or one or more information sources. Count reference questions concerning different topics from the same individual as separate questions. Exclude follow-up emails, multiple social media interactions, or other reference consultations on the same question." ${ }^{12}$ Intellectually, these guidelines present a clear and accurate way to quantify reference transactions. In practice, however, reference inquiries handled by multiple staff members potentially result in double counting, as well as inquiries with several follow-up exchanges. Public services staff previously tallied each response to a patron regardless of whether it was a follow-up or a new question, so the task force guidelines have introduced a change in practice for this measurement.

\section{Current and Future Applications of the Data Collected}

LSU Special Collections staff have now been tracking the new public services measures and metrics since July 2018. Gathering data using consistent and agreed-upon metrics naturally leads to the application of such data within the institution. The robust and comprehensive dataset derived from the new standards can inform a wide range of internal decisions. Given the recent approval of these standards and the time it takes to collect enough data to analyze it for trends, it may be too soon to expect new published studies describing the impact of the standards. At LSU, however, we envision using our data in some of the following ways.

Within public services units, it is common to adjust staffing by applying data from reading room operations. In the special collections field, patron visits can be unpredictable. Yet, with longer periods of data collection, trends can emerge. The number of daily visits to the reading room, the average number of hours researchers spend in the reading room per day of the week, and the busiest hours per week all help determine whether to add or reduce staff in the reading room, whether the library should be open on weekends, and perhaps which specific staff members to assign to which shifts. We could use reading room data to examine what time of day most undergraduate students visit Special Collections with the intention of offering workshops tailored to their research needs at those times.

The standards also provide extensive information related to collection use, including the number of items checked out by patrons in the reading room, items used by staff for reference requests, exhibits, instruction, and internal operations, and the number of reproduction requests or interlibrary loan requests received or completed. Utilizing these forms of data collection allow us to track the most used books or archival collections for the purpose of establishing digitization and processing priorities. Likewise, statistics on collection usage can also reveal what researchers are not requesting. We can generate reports listing each item (according to book or collection title) checked out more than 10 times within a given timeframe. Gaps in the results may correspond to a major acquisition that has not been promoted to the public or a valuable collection yet to be processed. This kind of data provides special collections staff with the evidence they need to make important decisions about internal priorities and to establish or update unit goals.

Use of special collections statistics to create user personas is currently underway to aid the LSU Libraries' website redesign project. As a member of the website redesign working group, I worked with a colleague to compile data available in Aeon for each of Special Collections' user groups (undergraduate students, graduate students, faculty, staff, and independent researchers). ${ }^{13}$ We tracked the number of unique visitors and total number of visits each group made to the reading room, as well as the number of collection items checked out in each format. Using information gathered from personal encounters with researchers, we wrote persona narratives describing typical member behaviors and actions from the five user groups. The scenarios will be used by LSU's web design vendor to analyze each department's needs and inform how the redesigned website will better serve our visitors.

\section{Conclusion}

The recent approval of the "Standardized Statistical Measures and Metrics for Public Services in Archival Repositories and Special Collections Libraries" is an important step forward in establishing consistent data collection methods across the field. While the implementation of the standards may vary across institutions, we must create better ways to report statistics in ways that map accordingly with the recommended 
measures and metrics in the SAA-ACRL/RBMS task force report. Data submitted from special collections and archives to bodies like ARL are often subsumed within the larger library system's data, preventing any sort of comparison among institutions. Improved national reporting will allow organizations to find natural peers in terms of staff size, collection size, annual visitors, and so forth.

Finally, while some argue that statistics can be used to reduce resources or staffing if certain benchmarks are not met, these types of statistical measures also help special collections and archives better serve researchers. The end goal to any type of data collection should be to empower institutions to make decisions that benefit both staff and library users. There is always a danger seeing only raw data and neglecting what the numbers truly convey. Tanya Zanish-Belcher, director of special collections and archives at Wake Forest University and the 2017-2018 president of the Society of American Archivists, asserts that, "numbers, statistics, and surveys are tools which can help us tell our story and share our value with others who may not understand the complexity and significance of what archivists do." ${ }^{14}$ The Standardized Statistical Measures and Metrics will undoubtedly help archivists and special collections librarians find peers and identify

similarities across the field, but they also have the power to show our user communities, stakeholders-and ourselves-that our organizations are as unique as the collections we steward, and we all have a story to tell.

-Copyright 2019 Amanda K. Hawk

\section{Endnotes}

1. "What are the Origins of ARL Statistics?" Association of Research Libraries, http://www.arlstatistics.org /about/origins.

2. "ARL Statistics," Association of Research Libraries, https://www.arlstatistics.org/About/Mailings /stats_2016-17.

3. Joyce Chapman and Elizabeth Yakel, "Data-Driven Management and Interoperable Metrics for Special Collections and Archives User Services," RBM: A Journal of Rare Books, Manuscripts, and Cultural

Heritage 13, no. 2 (2012): 129-151. Past efforts toward standardizing special collections metrics include the Society of American Archivists' Committee on Uniform Archival Statistics (1960) and Standard Reporting Practice Task Force (1980), and the Rare Books and Manuscripts Section Metrics and Assessment Task Force (2011).

4. Chapman and Yakel, "Data-Driven Management," 138-141.

5. See also Christian DuPont and Elizabeth Yakel, "What's So Special about Special Collections? Or, Assessing the Value Special Collections Bring to Academic Libraries," Evidence Based Library and Information Practice 8, no. 2 (2013): 9-21.

6. SAA-ACRL/RBMS Joint Task Force on the Development of Standardized Statistical Measures for Public Services in Archival Repositories and Special Collections Libraries, "Standardized Statistical Measures and Metrics for Public Services in Archival Repositories and Special Collections Libraries," 2017, https://www2.archivists.org/standards/standardized-statistical-measures-and-metrics-for-publicservices-in-archival-repositories.

7. See, for example, the purpose and responsibilities of the newly formed Society of American Archivists' Committee on Research, Data, and Assessment, accessed January 11, 2018, https://www2.archivists.org/governance/handbook/section7/groups/Research-Data-Assessment.

8. SAA-ACRL/RBMS Joint Task Force, "Standardized Statistical Measures and Metrics," 1-2.

9. For more information about the Aeon software, see https://www.atlas-sys.com/aeon/.

10. For more information about SpringShare's LibAnswers platform, see https://springshare.com/libanswers/.

11. The task force deems a "collection unit" a generic term that can equate to volume, archival unit, container, item, or piece. "This generic designation permits Repositories to perform circulation transactions and statistical counts in ways that are most sensible and practical locally, without attempting to require all institutions to count transactions in precisely the same way," SAA-ACRL/RBMS Task Force, "Standardized Statistical Measures and Metrics," 67.

12. SAA-ACRL/RBMS Task Force, "Standardized Statistical Measures and Metrics," 14. 
13. The undergraduate, graduate student, faculty, and staff patron statuses in Aeon include members of LSU's community as well as members of other colleges and universities. Every patron not associated with a higher education institution is categorized as "Independent Researcher."

14. Tanya Zanish-Belcher, "Evaluating Public Services in Special Collections," Midwest Archives Conference Annual Meeting, May 7, 2015, accessed January 12, 2018, https://www.midwestarchives.org/ccboard /27362969_b12a46860251466fb33faf0aed2411ca.pdf. 